\title{
Limb Remote Ischemic Preconditioning Applied During Sevoflurane Anesthesia Does Not Protect the Lungs in Patients Undergoing Adult Heart Valve Surgery
}

\author{
Tian-Yuan Li, ${ }^{1}$ Qing-Shi Zeng, ${ }^{2}$ Shou-Zhang She ${ }^{3}$ \\ ${ }^{1}$ Department of Anesthesiology, The First Affiliated Hospital of Nanchang University, Nanchang, Jiangxi, China; \\ ${ }^{2}$ Department of Anesthesiology, Guangdong General Hospital, Guangzhou, Guangdong, China; \\ ${ }^{3}$ Department of Anesthesiology, Guangzhou First People's Hospital, Guangzhou, Guangzhou, China
}

\section{ABSTRACT}

Background: Two consistent overall cell protective preconditioning treatments should provide more protection. We hypothesized that limb remote ischemic preconditioning (RIPC, second preconditioning stimulus) applied during sevoflurane inhalation (first preconditioning stimulus) would provide more protection to the lungs of patients undergoing adult heart valve surgery.

Methods: In this randomized, placebo-controlled, doubleblind trial, 50 patients were assigned to the RIPC group or the placebo group $(1: 1)$. Patients in the RIPC group received three 5-min cycles of $300 \mathrm{mmHg}$ cuff inflation/deflation of the left-side lower limb before aortic cross-clamping. Anesthesia consisted of opioids and propofol for induction and sevoflurane for maintenance. The primary end point was comparison of the postoperative arterial-alveolar oxygen tension ratio (a/A ratio) between groups. Secondary end points included comparisons of pulmonary variables, postoperative morbidity and mortality and regional and systemic inflammatory cytokines between groups.

Results: In the RIPC group, the a/A ratio and other pulmonary variables exhibited no significant differences throughout the study period compared with the placebo group. No significant differences in either plasma or bronchoalveolar lavage levels of TNF- $\alpha$ were noted between the groups at $10 \mathrm{~min}$ after anesthetic induction and $1 \mathrm{~h}$ after cross-clamp release. The percentage of neutrophils at $12 \mathrm{~h}$ postoperation was significantly increased in the RIPC group compared with the placebo group $(91.34 \pm 0.00$ vs. $89.42 \pm 0.10, P=0.023)$.

Conclusions: Limb RIPC applied during sevoflurane anesthesia did not provide additional significant pulmonary protection following adult valvular cardiac surgery.

Received fuly 16, 2021; accepted August 3, 2021.

Correspondence: Tian-Yuan Li, The First Affiliated Hospital of Nanchang University, Nanchang, Jiangxi, China (e-mail: berlinli456@163.com).

\section{INTRODUCTION}

Cardiopulmonary bypass (CPB) is widely applied in heart-opening operation, but it causes many serious complications, such as acute lung injury, with an incidence rate of up to $15 \% \sim 30 \%$ [Li 2013]. Therefore, methods to reduce lung injury after $\mathrm{CPB}$ are always the focus of clinical and experimental studies. Recently, a more clinically relevant stimulus has been afforded by remote ischemic preconditioning (RIPC), which involves the inflation and deflation of a tourniquet applied to skeletal muscle (usually the arm or limb) before a sustained ischemic period of the vital organs, and this procedure may confer cytoprotection. Limb RIPC has been shown to effectively reduce lung injury associated with ischemia/reperfusion (I/R) in patients without any potential risk [Li 2013; Zhou 2010]. On the other hand, volatile anesthetics (pharmacologic preconditioning) have been shown to mitigate I/R-induced lung injury [Faller 2017; Wagner 2018]. One study demonstrated that sevoflurane administered before ischemia can attenuate I/R-induced injury in isolated rat lungs [Liu 2000]. In addition, sevoflurane reduces I/R-induced inflammatory lung injury by inhibiting the release of TNF- $\alpha$ [Watanabe 2013; Yu 2013].

Schulz and coworkers revealed that the threshold concept of ischemic preconditioning, is a graded rather than an all-or-nothing phenomenon in anesthetized swine in situ [Schulz 1998; Zaugg 2003]. Thus, it would be conceivable that the application of two well-defined preconditioning stimuli should induce a more consistent and effective overall cell protection. Most previous studies in the field of ischemic and pharmacologic conditioning provide evidence that both types of preconditioning share many fundamental steps, including activation of G-protein-coupled receptors, multiple protein kinases, and ATP-sensitive potassium channels (KATP channels) [Loukogeorgakis 2007; Choi 2011]. In the present study, we tested whether RIPC executed on the lower limb (second preconditioning stimulus) would provide additional protective benefits to the pulmonary system in patients undergoing heart valve repair surgery with sevoflurane anesthesia (first preconditioning stimulus) by determining pulmonary function parameters as the primary outcome of the study. 


\section{MATERIALS AND METHODS}

A single-center, double-blinded, prospective, randomized, placebo-controlled trial following the CONSORT statement was conducted on patients undergoing elective valvular cardiac surgery. Written informed consent was obtained from each participant. The study protocol was reviewed and approved by the local ethics committee of Guangdong General Hospital (Guangdong, China). The trial was registered at the end of the study (ChiCTR-IOR-14005444).

Patients: The study was conducted at Guangdong General Hospital, Guangzhou, China, between September 2014 and November 2015. Adult patients consecutively were invited to participate in the current trial at the time they were scheduled for elective valvular cardiac surgery. Inclusion criteria were scheduled for elective heart valve repair surgery and age between 18-70 yrs. The following exclusion criteria were applied: body mass index greater than $35 \mathrm{~kg} /$ $\mathrm{m} 2$, emergency surgery, cardiac failure (NYHA class greater than II), peripheral vascular disease, a known history of COPD, pulmonary hypertension (mean pulmonary arterial pressure greater than $60 \mathrm{mmHg}$ ), or preexisting coagulation disorders.

Randomization and masking: Before the trial, randomized treatment allocations with no further stratification were generated by an independent person using a computer random number generator with a 1:1 allocation using blocks of varying sizes. Allocation details were stored in numbered, sealed, and opaque envelopes. Treatment allocation was revealed by anesthesiologists by opening the envelope on the morning of surgery and supervised by an independent statistician. None of the anesthesiologists participated in the data assessment or analysis and were not allowed to report study subjects' intervention to the intensive care unit (ICU) or surgical staff. Patients, investigators, surgeons, critical care teams, and individuals participating in data analysis were all blinded to group allocation. The trial was monitored by an independent data and safety monitoring board. Group allocation was not revealed until the final statistical analysis was completed. Baseline characteristics, intraoperative variables, and details of the postoperative course were recorded carefully for all patients.

Anesthetic and surgical management: FVC and FEV1 preoperatively were assessed using a handheld spirometer (Spirolab II; SDI Diagnostics, Rome, Italy). Operative and anesthetic techniques were standardized for the purpose of this trial. Both groups of patients were given general anesthesia with intravenous propofol $(1.5 \mathrm{mg} / \mathrm{kg})$, cisatracurium $(0.2 \mathrm{mg} / \mathrm{kg})$, and sufentanil $(0.5 \mu \mathrm{g} / \mathrm{kg})$. Maintenance of anesthesia was achieved with a continuous infusion of propofol $\left(2-3 \mathrm{mg} \cdot \mathrm{kg}^{-1} \cdot \mathrm{h}^{-1}\right)$, cisatracurium $\left(0.12 \mu \mathrm{g} \cdot \mathrm{kg}^{-1} \cdot \mathrm{min}^{-1}\right)$, 0.5-2 minimum alveolar concentration of sevoflurane and repetitive doses of opioids. Patients were intubated with a 7.5 - $\mathrm{mm}$ cuffed endotracheal tube, and the ventilation parameters were standardized (respiratory rate, $12-15$ breaths/ min; tidal volume, $6-8 \mathrm{ml} / \mathrm{kg}$; fraction of inspired oxygen, 0.6-1) to achieve 35-45 $\mathrm{mmHg}$ of ETCO2 in the expired air. In this study, patients initially received $5 \mathrm{cmH}_{2} \mathrm{O}$ positive

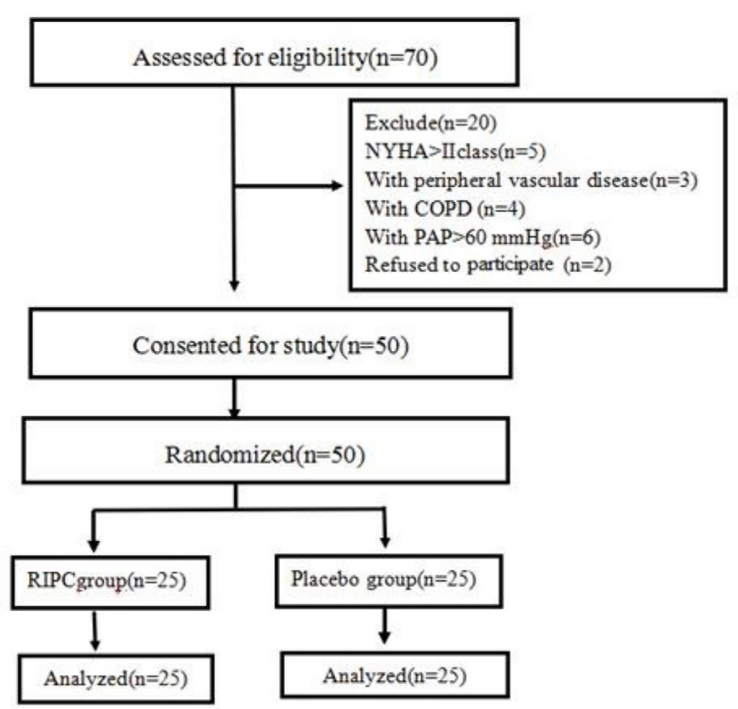

Figure 1. CONSORT diagram showing the flow of participants through each stage of the randomized trial. COPD, chronic obstructive pulmonary disease; NYHA, New York Heart Association; PAP, pulmonary arterial pressure

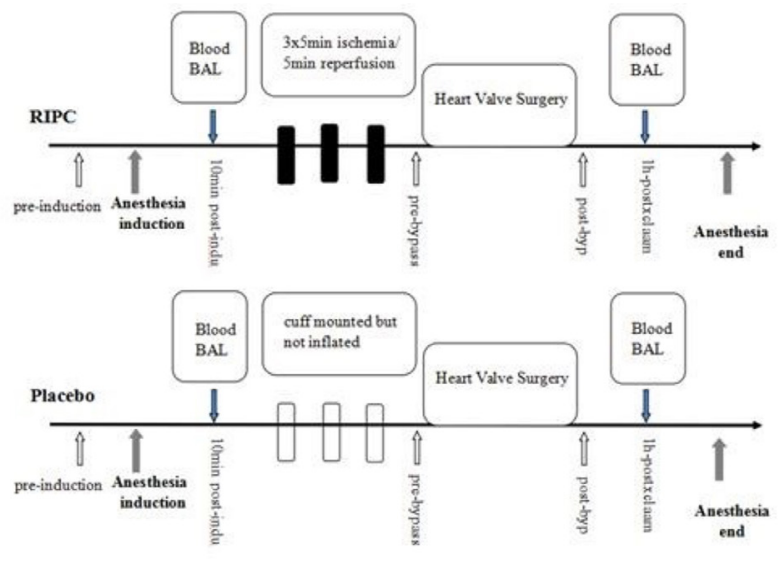

Figure 2. Preparation of blood samples and bronchoalveolar lavage (BAL)

end-expiratory pressure. If the patients' $\mathrm{PaO}_{2}$ was less than $80 \mathrm{mmHg}$, regular attempts were made to increase it, in 2 $\mathrm{cmH}_{2} \mathrm{O}$ increments, to achieve the goal $\left(\mathrm{PaO}_{2}>80 \mathrm{mmHg}\right.$, $\left.\mathrm{SpO}_{2}>95 \%\right)$. However, the maximal positive end-expiratory pressure was not greater than $10 \mathrm{cmH}_{2} \mathrm{O}$. Standardized fluid replacement consisted of $10 \mathrm{ml} / \mathrm{kg}$ lactated Ringer's solution applied preoperatively and $6 \mathrm{ml} / \mathrm{kg} / \mathrm{h}$ of the solution applied preoperatively. Colloids were administered to obtain a stable heart rate, central venous pressure of $8-10 \mathrm{cmH}_{2} \mathrm{O}$, steady mean arterial pressure, and a urine output greater than $1 \mathrm{ml} /$ $\mathrm{kg} / \mathrm{h}$. Packed erythrocytes were transfused as necessary to maintain a circulating hemoglobin level of approximately 10 $\mathrm{g} / \mathrm{dl}$. Fresh frozen plasma and cryoprecipitate were transfused to improve coagulation function according to the thrombus elastic figure. All patients underwent surgical repairs using standard CPB techniques with cardioplegic arrest, and 
sevoflurane was administered through the CPB machine. Modified ultrafiltration was performed in all patients. Fluid balance and the amount of blood loss and transfusion during the operation were recorded.

Postoperative management: At the end of surgery, the patients were routinely transferred to the ICU for weaning from artificial ventilation. All patients received intravenous analgesia with a $100 \mathrm{ml}$ mixture of $0.2 \mathrm{mg} / \mathrm{kg}$ tropisetron and 4 $\mathrm{ug} / \mathrm{kg}$ sufentanil with a basal rate of $2 \mathrm{ml} / \mathrm{h}$, bolus doses of 2-3 $\mathrm{ml}$, and a lockout interval of 20 minutes. To ensure that those patients had a working intravenous analgesia, postoperative pain was assessed at rest and movement during postoperative days 1, 2, and 3 using the visual analog scale rating from 0 (no pain at all) to 10 (worst possible pain). In the ICU, crystalloid fluid replacement was infused at $2 \mathrm{ml} / \mathrm{kg} / \mathrm{h}$ to maintain a stable heart rate, central venous pressure of 8-10 $\mathrm{cm} \mathrm{H}_{2} \mathrm{O}$, and a steady mean arterial pressure. In addition, blood was given to maintain hemoglobin at greater than $10 \mathrm{~g} / \mathrm{dl}$. Extubation was managed according to the standard ICU protocols by the ICU staff. The ICU extubation protocol included adequate oxygenation $\left(\mathrm{PaO}_{2} \geq 60 \mathrm{mmHg}, \mathrm{PaCO} 2 \leq 50 \mathrm{mmHg}\right.$ on a fraction of inspired oxygen $\leq 40 \%$, positive end-expiratory pressure $\leq 8 \mathrm{~cm} \mathrm{H}_{2} \mathrm{O}$ ), systolic blood pressure greater than 90 $\mathrm{mmHg}$ without vasopressor support, heart rate greater than 60 beats/minutes, absence of significant metabolic/respiratory acidosis $(\mathrm{pH} \geq 7.3)$, adequate hemoglobin level $(8-10 \mathrm{~g}$ / $\mathrm{dl}$ ), and spontaneous breathing (spontaneous $\mathrm{VT} \geq 4 \mathrm{ml} / \mathrm{kg}$, and respiratory rate $\leq 35$ per minutes). For each patient, the postoperative ventilator support time and ICU and hospitalfree days were recorded.

RIPC protocol: Details of the study protocol are provided in Figure 2. A $15-\mathrm{cm}$ sterile blood pressure cuff was placed around the left thigh and connected to the inflating device. Subsequently, the patient was randomly allocated (by opening of an envelope) to RIPC consisting of three 5-minute cycles of lower limb I/R induced by a tourniquet inflated to $300 \mathrm{mmHg}$ or placebo, i.e., no treatment. This procedure was executed by one nurse not otherwise involved in the study. All patients were transferred to the ICU, where they received the same standardized routine postoperative care. (Figure 2)

Blood samples were collected for analysis at the following time points: 10 minutes after anesthetic induction (baseline, T1) and 1 (T2), 4 (T3), 8 (T4), 12 (T5), and 24 h (T6) after cross-clamp release. Venous blood was sampled from the jugular venous line and centrifuged at $3000 \mathrm{rpm}$ for $15 \mathrm{~min}$. Plasma samples were stored at $-70^{\circ} \mathrm{C}$ for subsequent analysis. Radial arterial blood was analyzed using a blood gas system (GEM Premier 3000, Instrumentation Laboratory, Bedford, MA).

BAL was performed by sequential instillation and gentle aspiration of isotonic sodium chloride solution (10-ml portions, for a total of $20 \mathrm{ml}$ ) with fiberoptic bronchoscopy in the right main bronchus after intubation and $1 \mathrm{~h}$ after crossclamp release.

Assessment of pulmonary injury: Pulmonary function evaluation included the a/A ratio, $\mathrm{A}-\mathrm{aDO}_{2}$, oxygenation index (OI), and respiratory index (RI) at corresponding time points. Respiratory compliance was measured for $4 \mathrm{~h}$ after cross-clamp release. During mechanical ventilation, $\mathrm{Vt}, \mathrm{FiO}_{2}$,
Pmax, Pplat, and PEEP were obtained directly from the ventilator setting (S/5 Aespire 7900; Datex-Ohmeda, Madison, Wisconsin). The following formulas were used to determine pulmonary function:

$$
\begin{aligned}
& \text { Static lung compliance }(\mathrm{Cs})=\mathrm{Vt} /(\mathrm{Pplat}-\mathrm{PEEP}) \\
& \text { Dynamic lung compliance }(\mathrm{Cd})=\mathrm{Vt} /(\mathrm{Pmax}-\mathrm{PEEP}) \\
& \text { a/A ratio }=\mathrm{PaO}_{2} / \mathrm{PAO}_{2} \\
& \mathrm{~A}-\mathrm{aDO} \mathrm{O}_{2}=\mathrm{PAO}_{2}-\mathrm{PaO}_{2}=\left(713 \mathrm{FiO}_{2}-\mathrm{PaCO}_{2} / 0.8\right)-\mathrm{PaO}_{2} \\
& \mathrm{RI}=\mathrm{A}-\mathrm{aOO}_{2} / \mathrm{PaO}_{2} \\
& \mathrm{OI}=\mathrm{PaO}_{2} / \mathrm{FiO}_{2}
\end{aligned}
$$

Evaluation of inflammatory response: Plasma and BAL levels of TNF- $\alpha$ were measured between the groups at 10 minutes after anesthetic induction and $1 \mathrm{~h}$ after cross-clamp release using a sandwich enzyme-linked immunoassay with the RayBio ${ }^{\circledR}$ Human TNF-alpha ELISA kit (The Protein Array Pioneer Company, Guangzhou, China). Furthermore, WBC count; percentage of neutrophil count; and hepatic and renal function were measured pre-operation and 12 and $24 \mathrm{~h}$ after the cross-clamp release from venous blood.

Primary and secondary study outcomes: The primary outcome was a/A ratio. Secondary outcomes included (1) other variables reflecting pulmonary injury (OI,A-aDO, $\mathrm{RI}, \mathrm{Cs}, \mathrm{Cd}$ ); (2) markers of regional and systemic inflammatory response; (3) duration of ventilatory care; (4) duration of ICU stay; (5) postoperative recovery time from operation day to hospital discharge; and (6) hepatic and renal dysfunction.

Sample size calculation: The primary end point was to compare the lowest postoperative $\mathrm{PaO}_{2}$. We determined that 22 patients would be required in each group for $80 \%$ power to detect a $51 \mathrm{mmHg}$ difference in $\mathrm{PaO}$, between the groups at an $\mathrm{FiO}_{2}$ of 0.4 with an $\mathrm{SD}$ of $60 \mathrm{mmHg}$ and of 0.05 based on an independent $t$ test [Choi 2011]. Allowing for a $10 \%$ drop-out rate during the study period, 25 patients were enrolled for each group.

Statistical analysis: Statistical analyses were performed with SPSS, version 19 (SPSS Inc.). Continuous data are expressed as the mean \pm SD or median $(25 \%$ percentile, $75 \%$ percentile) of patients and were compared with independent $t$ test or Mann-Whitney U test, respectively. Categorical data are expressed as frequencies or percentages and were compared with Fisher's exact test or the chi-square test, where appropriate. All data, including the pulmonary outcomes, hemodynamic data, and biochemical serum markers, were analyzed using two-way repeated-measures ANOVA with Bonferroni correction for both within-group and betweengroup comparisons. All $P$-values were two-sided, and the statistical significance level was 0.05 .

\section{RESULTS}

All 50 patients successfully were weaned from CPB without the aid of any mechanical assist device, and no one developed complications related to RIPC intervention. Patient characteristics, preoperative laboratory data, and surgical types were similar between the groups. (Table 1) 
Table 1. Preoperative patient characteristics

\begin{tabular}{|c|c|c|c|}
\hline \multicolumn{4}{|l|}{ Demographics } \\
\hline Gender (male) & 12 & 10 & 0.569 \\
\hline Weight (kg) & $59.4 \pm 3.1$ & $51.4 \pm 2.2$ & 0.353 \\
\hline Smoking, (n, \%) & - & - & 0.816 \\
\hline Current smokers & $3(12)$ & $2(8)$ & \\
\hline Ex-smokers & $10(40)$ & $9(36)$ & \\
\hline Never smoked & $12(48)$ & $14(56)$ & \\
\hline \multicolumn{4}{|l|}{ Associated illness, (n, \%) } \\
\hline Type of surgical procedure, (n, \%) & - & - & 0.673 \\
\hline DVR & $9(36)$ & $7(28)$ & \\
\hline MVR & $2(8)$ & $4(16)$ & \\
\hline $\mathrm{MVR}+\mathrm{TAP}$ & $10(40)$ & $8(32)$ & \\
\hline AVR & $4(16)$ & $6(24)$ & \\
\hline \multicolumn{4}{|l|}{ Lab results } \\
\hline HGB & $134.0 \pm 3.7$ & $130.9 \pm 2.9$ & 0.766 \\
\hline НCT (\%) & $39.7 \pm 0.9$ & $39.3 \pm 0.9$ & 0.821 \\
\hline CRP & $2.7 \pm 0.3$ & $2.3 \pm 0.3$ & 0.788 \\
\hline
\end{tabular}

Data are presented as mean \pm SD or number (\%). There were no differences between the two groups. HGB, hemoglobin; RIPC, remote ischemic preconditioning; AVR, aortic valve replacement; DVR, double-valve replacement; LVEF, left ventricular ejection fraction; MVR, mitral valve replacement; TAP, tricuspid annuloplasty; CRP, C-reactive protein; HCT, haematocrit; FEV1, forced expiratory volume in 1 second; FVC, forced vital capacity

As shown in Table 2, no significant differences in fluid balance or transfusion requirements were noted between the groups during the operation. (Table 2) Perioperative hemodynamic variables and arterial $\mathrm{pH}$ were similar between the groups throughout the study period. (Table 3)

No significant differences in pulmonary variables, including a/A ratio, OI, Cs, $\mathrm{Cd}, \mathrm{A}-\mathrm{aDO}_{2}$, or $\mathrm{RI}$ were noted between the two groups over time. (Table 4) Plasma and BAL levels of the inflammatory marker TNF- $\alpha$ were not different between the groups throughout the study period. All values in both groups were significantly increased after the operation compared with baseline. The percentage of neutrophils $12 \mathrm{~h}$ after cross-clamp release was significantly increased in the RIPC group compared with the placebo $(91.34 \pm 0.00$ vs. $89.42 \pm 0.10, P=0.023$, the WBC count was not altered. In the limb RIPC group, the WBC count and percentage of neutrophils preoperatively and $24 \mathrm{~h}$ after cross-clamp release were not significantly different compared with the placebo group. (Table 5)

The duration of mechanical ventilation, ICU stay, and postoperative recovery time also were similar between the RIPC and placebo groups. (Table 6)

\section{DISCUSSION}

The concept of RIPC was first introduced by Przyklenk et al. [Przyklenk 1993] The initial study suggested that one vascular bed could precondition another vascular bed in dogs. The basic concept was followed by additional studies suggesting that transient ischemia of the limb could also induce protection for organs against subsequent I/R injury.

Recently, RIPC drew attention as a pulmonary-protective intervention against I/R injury in cardiac surgery. $\mathrm{Li}$ et al. [Li 
Table 2. Intraoperative and postoperative data

\begin{tabular}{lccc}
\hline & RIPC $(N=25)$ & Placebo $(N=25)$ & $P$-value \\
\hline Surgery time (min) & $251 \pm 13$ & $218 \pm 9$ & 0.649 \\
Bypass time (min) & $125 \pm 8$ & $108 \pm 8$ & 0.311 \\
Cross-clamp time (min) & $90 \pm 6$ & $72 \pm 7$ & 0.143 \\
Crystalloid (ml) & $1170 \pm 74$ & $1356 \pm 57$ & 0.099 \\
Colloid (ml) & $1020 \pm 64$ & $678 \pm 104$ & 0.093 \\
Estimate blood loss (ml) & $275 \pm 13$ & $280 \pm 23$ & 0.621 \\
Urine output (ml) & $875 \pm 214$ & $639 \pm 93$ & 0.494 \\
Ultrafiltration volume (ml) & $1640 \pm 165$ & $1583 \pm 162$ & 0.436 \\
Number of patients transfused (\%) & & $2(8)$ \\
$\quad$ P-RBC & $2(8)$ & $4(16)$ & 0.639 \\
FFP & $2(8)$ & $1.7 \pm 0.9$ & $0.75 \pm 0.4$ \\
$\quad$ Cryoprecipitate & $1(4)$ & $2.9 \pm 0.2$ & 0.727 \\
Average [sevoflurane] vol\% end-tidal & $1.8 \pm 0.8$ & 0.666 \\
Min [sevoflurane] vol\% end-tidal & $0.56 \pm 0.3$ & \\
Max [sevoflurane] vol\% end-tidal & $3.0 \pm 0.1$ & & \\
\hline
\end{tabular}

Data are presented as mean \pm SD or number (\%). FFP, fresh frozen plasma; p-RBC, packed red blood cell

Table 3. Hemodynamic data

\begin{tabular}{|c|c|c|c|c|c|c|c|}
\hline $\mathrm{MAP}(\mathrm{mmHg})$ & Placebo & $76 \pm 2$ & $72 \pm 2$ & $79 \pm 3$ & $80 \pm 1$ & $85 \pm 2$ & $85 \pm 2$ \\
\hline \multirow[t]{2}{*}{ HR (beats/min) } & Placebo & $81 \pm 5$ & $94 \pm 4^{a}$ & $90 \pm 3^{\mathrm{a}}$ & $92 \pm 3^{\mathrm{a}}$ & $93 \pm 2^{a}$ & $91 \pm 4$ \\
\hline & RIPC & $81 \pm 5$ & $92 \pm 4^{\mathrm{a}}$ & $90 \pm 3$ & $87 \pm 2$ & $85 \pm 3$ & $88 \pm 3$ \\
\hline $\mathrm{HGB}(\mathrm{g} / \mathrm{l})$ & RIPC & $126.1 \pm 3.5$ & $93.5 \pm 4.1$ & $113.2 \pm 4.2$ & $113.8 \pm 4.2$ & $113.2 \pm 3.2$ & $115.4 \pm 4.0$ \\
\hline \multirow[t]{2}{*}{ HCT (\%) } & Placebo & $40.4 \pm 1.1$ & $31.8 \pm 0.9^{a}$ & $33.5 \pm 1.0$ & $34.0 \pm 1.0$ & $33.4 \pm 0.6^{a}$ & $32.8 \pm 0.8$ \\
\hline & RIPC & $9.2 \pm 1.1$ & $29.6 \pm 1.4$ & $34.8 \pm 1.2^{\mathrm{a}}$ & $35.0 \pm 1.3$ & $34.8 \pm 0.9$ & $35.5 \pm 1.2$ \\
\hline \multirow[t]{2}{*}{ Arterial pH } & Placebo & $7.47 \pm 0.01$ & $7.43 \pm 0.01$ & $7.37 \pm 0.02$ & $7.37 \pm 0.01$ & $7.37 \pm 0.01$ & $7.40 \pm 0.01$ \\
\hline & RIPC & $7.42 \pm 0.02$ & $7.41 \pm 0.02$ & $7.42 \pm 0.02$ & $7.38 \pm 0.01$ & $7.38 \pm 0.01$ & $7.41 \pm 0.01$ \\
\hline
\end{tabular}

Data are presented as mean \pm SD. MAP, mean arterial pressure; HR, heart rate. T1 = 10 min after induction; T2 = $1 \mathrm{~h}$ after reperfusion; T3 = $4 \mathrm{~h}$ after reperfu-

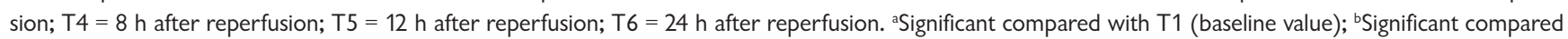
with the placebo.

2013] reported that limb RIPC attenuates pulmonary injury in patients undergoing elective open infrarenal abdominal aortic aneurysm repair without any potential risk. On the other hand, Lucchinetti et al. [Lucchinetti 2007] reported human endothelium, a key component of all vital organs, is receptive to protection by sevoflurane in vivo and that periischemic administration of sevoflurane mimics a combination of pharmacologic preconditioning and postconditioning and protects at even low sedative concentrations (< $1 \mathrm{vol} \%$ ). Anesthetic preconditioning (APC) with sevoflurane attenuates I/R induced lung injury in animal models [Steurer 2009; Liu 1999]. 
Table 4. Data of perioperative pulmonary function

\begin{tabular}{|c|c|c|c|c|c|c|c|}
\hline a/A ratio (\%) & Placebo & $82 \pm 2$ & $80 \pm 4$ & $68 \pm 4$ & $83 \pm 6^{a}$ & $85 \pm 5^{a}$ & $94 \pm 9^{a}$ \\
\hline \multirow[t]{2}{*}{$\mathrm{A}-\mathrm{aDO}{ }_{2}(\mathrm{mmHg})$} & Placebo & $98 \pm 15$ & $112 \pm 20$ & $94 \pm 14$ & $71 \pm 13$ & $50 \pm 9$ & $13 \pm 15^{\mathrm{a}}$ \\
\hline & RIPC & $101 \pm 19$ & $117 \pm 27$ & $118 \pm 18$ & $105 \pm 20$ & $61 \pm 9^{a}$ & $21 \pm 12$ \\
\hline RI & RIPC & $0.24 \pm 0.05$ & $0.33 \pm 0.10$ & $0.64 \pm 0.11^{\mathrm{a}}$ & $0.70 \pm 0.21^{\mathrm{a}}$ & $0.34 \pm 0.08$ & $0.17 \pm 0.09$ \\
\hline \multirow[t]{2}{*}{ Ol } & Placebo & $542 \pm 13$ & $515 \pm 23$ & $413 \pm 24$ & $493 \pm 37^{a}$ & $486 \pm 29^{a}$ & $589 \pm 59^{a}$ \\
\hline & RIPC & $536 \pm 19$ & $508 \pm 26$ & $392 \pm 24$ & $394 \pm 29$ & $458 \pm 37$ & $511 \pm 32^{a}$ \\
\hline \multirow[t]{2}{*}{$\mathrm{Cs}\left(\mathrm{ml} \cdot \mathrm{cm}-1 \cdot \mathrm{H}_{2} \mathrm{O}\right)$} & Placebo & $47.89 \pm 4.58$ & $49.20 \pm 4.07$ & $97.92 \pm 15.85^{\mathrm{a}}$ & & & \\
\hline & RIPC & $58.18 \pm 7.51$ & $59.12 \pm 6.34$ & $126.42 \pm 23.51^{\mathrm{a}}$ & & & \\
\hline
\end{tabular}

Data are presented as mean $\pm \mathrm{SD}$. a/A ratio, arterial-alveolar; $\mathrm{A}-\mathrm{aDO}$, alveolar-arterial oxygen tension difference; Cd, dynamic lung compliance; Cs, static lung compliance; RI, respiratory index; OI, oxygenation index. ${ }^{a}$ Significant compared with T1 (baseline value).

Table 5. Inflammatory markers

\begin{tabular}{|c|c|c|c|c|c|}
\hline WBC count & Placebo & $6.47 \pm 0.30$ & - & $15.09 \pm 1.17$ & $18.17 \pm 1.33$ \\
\hline \multirow[t]{2}{*}{ Neutrophil count, \% } & Placebo & $57 \pm 3$ & - & $89 \pm 1$ & $91 \pm 1$ \\
\hline & RIPC & $58 \pm 2$ & - & $91 \pm 0^{\mathrm{b}}$ & $91 \pm 1$ \\
\hline TNF- $\alpha, p g / m l$ (plasma) & RIPC & $62.84 \pm 7.95$ & $113.85 \pm 23.54$ & & \\
\hline \multirow[t]{2}{*}{ TNF- $\alpha, p g / m l(B A L)$} & Placebo & $51.11 \pm 7.42$ & $100.65 \pm 23.16$ & & \\
\hline & RIPC & $76.72 \pm 12.05$ & $113.44 \pm 20.78$ & & \\
\hline
\end{tabular}

Data are presented as mean \pm SD. TNF- $\alpha=$ tumor necrosis factor- $\alpha$; BAL, bronchoalveolar lavage. ${ }^{b}$ Significant compared with the placebo.

Table 6. Postoperative morbidity and mortality

\begin{tabular}{lccc}
\hline Outcome variables & RIPC $(N=25)$ & Placebo $(N=25)$ & $P$-value \\
\hline Duration of ventilatory care, $\mathrm{h}$ & $10.40 \pm 1.12$ & $11.08 \pm 1.07$ & 0.759 \\
Acute hepatic dysfunction, $(\mathrm{n}, \%)$ & $4(16)$ & $4(16)$ & 1.000 \\
Acute renal dysfunction, $(\mathrm{n}, \%)$ & $2(8)$ & $21.33 \pm 2.78$ & 1.000 \\
Duration of ICU stay, $\mathrm{h}$ & $23.40 \pm 2.78$ & $13.17 \pm 1.55$ & 0.689 \\
Postoperative recovery time, $\mathrm{d}$ & $11.50 \pm 1.83$ & 0.621 \\
\hline
\end{tabular}

Data are presented as mean \pm SD or number (\%) 
To intensify the organ-protective effects through ischemic conditioning, various attempts have been performed, including a combination of local and remote ischemic conditioning [Xin 2010], a combination of ischemic preconditioning and postconditioning [Knudsen 2011], and an increase in the number and intensity of ischemic conditioning [Sandhu 1997; Schulz 1998]. Therefore, we tested whether the combination of limb RIPC and sevoflurane anesthesia would provide additional protective benefit to the lungs in patients undergoing heart valve repair surgery. According to the threshold theory of preconditioning, including both ischemic and pharmacologic preconditioning, it could be expected that the application of two well-defined preconditioning- stimuli, namely RIPC and sevoflurane, in our study should indeed induce more consistent and effective overall cell protection. In the present study, however, RIPC neither improved the primary end point $\left(\mathrm{PaO}_{2} / \mathrm{PAO}_{2}\right)$ compared with the placebo group nor reduced the duration of ventilatory care or ICU stay. In this small trial, no clinical improvements were associated with these results.

Modulating inflammatory responses is a well-known mechanism of RI-induced organ protection [Hausenloy 2005; Xu 2011]. The CPB-induced inflammatory reaction is thought to be the main cause of lung injury, and recent work has indicated that TNF- $\alpha$ is an essential component of the cascade of events that lead to I/R-induced lung injury [Khimenko 1998; Colletti 1998]. Furthermore, blockade of TNF- $\alpha$ can reduce neutrophil chemotaxis and sequestration and attenuate the lung injury process [Tassiopoulos 1998]. Thus, we investigated TNF- $\alpha$ levels in BAL and plasma to evaluate the inflammatory reaction in the lungs after I/R injury. In addition, ischemia and subsequent reperfusion of the aorta may induce a systemic inflammatory response associated with the sequestration of polymorphonuclear leucocytes (neutrophils) in the lungs [Adembri 2004; Pararajasingam 2000; Sookhai 2002; Tassiopoulos 1998].

Neutrophil sequestration and activation have been suggested to be major contributing factors to acute lung injury and acute respiratory distress syndrome [Lee 2001; Reutershan 2004; Moraes 2006; Ng 2006]. In the present study, however, we could not find any evidence of RIPC modulating the inflammatory response either systemically or regionally. The current results are consistent with those of a study that Jong-Chan Kim et al. [Kim 2012] reported.

The possible explanations for this negative outcome of the RIPC group on lung protection in the current study are as follows. First, according to the threshold theory of preconditioning, the combination of two independent subthreshold stimuli may exert additional protective effects. Conversely, if the maximum preconditioning trigger stimulus has already been reached with an approximately 1.0 -2.0 minimum alveolar concentration of sevoflurane alone, as used in our study, the ischemic stimulus by RIPC may become redundant, and the net result would be a lack of synergy. In support of this concept, Obal et al. [Obal 2001] demonstrated the highest degree of protection by sevoflurane conditioning with 1 MAC compared with 2 MACs in an in vivo rat model.
Second, the application of RIPC under general anesthesia is an ineffective method to achieve vital organ protection because anesthetic-induced preconditioning and ischemic preconditioning share many fundamental steps. In addition, anesthetics are known to mitigate the ischemic response in the human body necessary to elicit the preconditioned state. Propofol, a commonly used intravenous anesthesia drug, is structurally similar to vitamin $\mathrm{E}$ and has been shown to attenuate I/R-induced lung injury in various experimental settings [Votta-Velis 2007; Takao 2005; Balyasnikova 2005]. Similarly, opioids activate $\delta$ - and $\kappa$-opioid receptors which can produce preconditioning and protection from organ I/R injury in experimental animals and in patients [Schultz 1996; Tomai 1999]. In addition, steroids used in this study, could also influence the RIPC effect. The anti-inflammatory effect of a previously administered steroid might block the beneficial inflammatory process induced by RIPC.

Third, what do we know from the effect of combined ischemic and pharmacologic preconditioning in studies? Animal experiments demonstrated that ischemic preconditioning showed no protective effect in I/R injury when pharmacologic preconditioning (isoflurane or sevoflurane) was administered concomitantly [Vianna 2009; Kuzume 2004]. However, if administered sequentially, it provided synergistic effects [Toller 1999; Fudickar 2014]. Lucchinetti et al. [Lucchinetti 2012] reported that RIPC combined with isoflurane administered concomitantly provided no additional benefit to the myocardium and revealed a lack of synergy or evidence of antagonism in cardioprotection in both strategies. Taken together, these studies provide evidence of antagonism rather than lack of synergy between ischemic and pharmacologic preconditioning and suggest that anesthetics attenuate or even abolish RIPC when administered concomitantly.

Fourth, the correct "dose" of ischemia, including the cuff pressure, stimulus size, site, and timing used in the study, is unknown specifically during concomitant anesthesia. Although the study did not provide information regarding pulmonary outcome, the stimulus size was combination of the upper limb and lower limb [Wu 2011].

Our findings have important clinical implications. RIPC remains a promising strategy to provide protection to the entire body specifically when pharmacologic preconditioning (isoflurane or sevoflurane) is administered sequentially.

There are several limitations in the current study. First, the sample size was calculated based on the a/A ratio, and this would be smaller than a sample size based on a clinically significant end point such as ALI. Therefore, such a clinical difference cannot be excluded. Second, further studies should be performed to determine which mode of RIPC (upper and lower limb RIPC or a higher cuff pressure) is more effective for protection of organs and what ischemic level could confer better beneficial effects. Third, although we tried to exclude potential interferences, some factors, such as anesthetic agents [Hirata 2011], ages [Liu 2009], and diabetes [Amour 2010], could interfere with the effects of RIPC, which might have confounded the results. 
CONCLUSION

Our study suggests that RIPC provides no additional pulmonary benefit following adult valvular cardiac surgery when sevoflurane is administered concomitantly.

\section{REFERENCES}

Adembri C, Kastamoniti E, Bertolozzi L, et al. 2004. Pulmonary injury follows systemic inflammatory reaction in infrarenal aortic surgery. Crit Care Med. 32: 1170-1177.

Amour J, Brzezinska AK, Jager Z, Sullivan C, Weihrauch D, Du J, Vladic N, Shi Y, Warltier DC, Pratt PF Jr, Kersten JR. 2010. Hyperglycemia adversely modulates endothelial nitric oxide synthase during anesthetic preconditioning through tetrahydrobiopterin and heat shock protein 90-mediated mechanisms. Anesthesiology. 112:576.

Balyasnikova IV, Visintine DJ, Gunnerson HB, et al. 2005. Propofol attenuates lung endothelial injury induced by ischemia-reperfusion and oxidative stress. Anesth Analg. 100:929-36.

Choi YS, Shim JK, Kim JC, et al. 2011. Effect of remote ischemic preconditioning on renal dysfunction after complex valvular heart surgery: a randomized controlled trial. J Thorac Cardiovasc Surg. 142 (1): 148-154.

Colletti L, Cortis A, Lukacs N, Kunkel S, Green M, Strieter R. 1998. Tumor necrosis factor up-regulates intercellular adhesion molecule 1, which is important in the neutrophil-dependent lung and liver injury associated with hepatic ischemia and reperfusion in the rat. Shock. 10:182-91.

Faller S, Seiler R, Donus R, Engelstaedter H, Hoetzel A, Spassov SG.Faller S, et al. 2017. Pre- and posttreatment with hydrogen sulfide prevents ventilator-induced lung injury by limiting inflammation and oxidation. PLoS One. 28;12(4):e0176649.

Fudickar A, Kunath S, Voß D, Siggelkow M, Cavus E, Steinfath M, Bein B. 2014. Effect of ischemic and pharmacological preconditioning of lower limb muscle tissue on tissue oxygenation measured by near-infrared spectroscopy - a pilot study. BMC Anesthesiology. 14:54.

Hausenloy DJ, Tsang A, Mocanu MM, Yellon DM. 2005. Ischemic preconditioning protects by activating prosurvival kinases at reperfusion. Am J Physiol Heart Circ Physiol. 288 (2):H971 - H976.

Hirata N, Shim YH, Pravdic D, Lohr NL, Pratt PF Jr, Weihrauch D, Kersten JR, Warltier DC, Bosnjak ZJ, Bienengraeber M. 2011. Isoflurane differentially modulates mitochondrial reactive oxygen species production via forward versus reverse electron transport flow: Implications for preconditioning. Anesthesiology. 115:531-40.

Khimenko P, Bagby G, Fuseler J, Taylor A. 1998. Tumor necrosis factor alpha in ischemia and reperfusion injury in rat lung. J Appl Physiol. 85:2005-11.

Kim JC, Shim JK, Lee S, Yoo YC, Yang SY, Kwak YL. 2012. Effect of Combined Remote Ischemic Preconditioning and Postconditioning on Pulmonary Function in Valvular Heart Surgery. CHEST. 142(2):467-475.

Knudsen AR, Kannerup AS, Grønbæk H, et al. 2011. Effects of ischemic pre- and postconditioning on HIF-1 a, VEGF and TGF-b expression after warm ischemia and reperfusion in the rat liver. Comp Hepatol. 10 (1): 3.

Kuzume K, Wolff RA, Chien GL, Van Winkle DM. 2004. Remifentanil limits infarct size but attenuates preconditioning-induced infarct limitation. Coron Artery Dis. 15:449-55.
Lee WL, Downey GP. 2001. Neutrophil activation and acute lung injury. Curr Opin Crit Care. 7: 1-7.

Li C, Li YS, Xu M, Wen SH, Yao X, Wu Y, Huang CY, Huang WQ, Liu KX. 2013. Limb remote ischemic preconditioning for intestinal and pulmonary protection during elective open infrarenal abdominal aortic aneurysm repair: a randomized controlled trial. Anesthesiology. 118(4):842-52.

Liu L, Zhu J, Glass PS, Brink PR, Rampil IJ, Rebecchi MJ. 2009. Age associated changes in cardiac gene expression after preconditioning. Anesthesiology. 111:1052-64.

Liu R, Ishibe Y, Ueda M. 2000. Isoflurane-sevoflurane administration before ischemia attenuates ischemia-reperfusion-induced injury in isolated rat lungs. Anesthesiology. 92:833-40.

Liu R, Ishibe Y, Ueda M, Hang Y. 1999. Isoflurane administration before ischemia and during reperfusion attenuates ischemia/reperfusioninduced injury of isolated rabbit lungs. Anesth Analg. 89:561-5.

Loukogeorgakis SP, Williams R, Panagiotidou AT, Kolvekar SK, Donald A, Cole TJ, Yellon DM, Deanfield JE, MacAllister RJ. 2007. Transient limb ischemia induces remote preconditioning and remote postconditioning in humans by a K(ATP)-channel dependent mechanism. Circulation. 116:1386-95.

Lucchinetti E, Ambrosio S, Aguirre J, Herrmann P, Härter L, Keel M, Meier T, Zaugg M. 2007. Sevoflurane inhalation at sedative concentrations provides endothelial protection against ischemia-reperfusion injury in humans. ANESTHESIOLOGY. 106:262-8.

Lucchinetti E, Bestmann U, Feng J, Freidank H, Clanachan AS, Finegan BA, Zaugg M. 2012. Remote Ischemic Preconditioning Applied during Isoflurane Inhalation Provides No Benefit to the Myocardium of Patients Undergoing On-pump Coronary Artery Bypass Graft Surgery: Lack of Synergy or Evidence of Antagonism in Cardioprotection? Anesthesiology. 116:296-310.

Moraes TJ, Zurawska JH, Downey GP. 2006. Neutrophil granule contents in the pathogenesis of lung injury. Curr Opin Hematol. 13: 21-27.

Ng CS, Wan S, Arifi AA, Yim AP. 2006. Inflammatory response to pulmonary ischemia-reperfusion injury. Surg Today. 36: 205-214.

Obal D, Preckel B, Scharbatke H, Mullenheim J, Hoterkes F, Thamer V, Schlack W. 2001. One MAC of sevoflurane provides protection against reperfusion injury in the rat heart in vivo. Br J Anaesth. 87:905-11.

Pararajasingam R, Weight SC, Bell PR, Nicholson ML, Sayers RD. 2000. Pulmonary nitric oxide metabolism following infrarenal aortic cross-clamp-induced ischaemia-reperfusion injury. Eur J Vasc Endovasc Surg. 19: 47-51.

Przyklenk K, Bauer B, Ovize M, Kloner RA, Whittaker P. 1993. Regional ischemic 'preconditioning' protects remote virgin myocardium from subsequent sustained coronary occlusion. Circulation. 87:893-9.

Reutershan J, Ley K. 2004. Bench-to-bedside review: acute respiratory distress syndrome - how neutrophils migrate into the lung. Crit Care. 8: 453-461.

Sandhu R, Diaz RJ, Mao GD, Wilson GJ. 1997. Ischemic preconditioning: differences in protection and susceptibility to blockade with singlecycle versus multicycle transient ischemia. Circulation. 96 (3): 984-995.

Schultz JEJ, Hsu AK, Gross GJ. 1996. Morphine mimics the cardioprotective effect of ischemic preconditioning via a glibenclamide-sensitive mechanism in the rat heart. Circ Res. 78:1100-4.

Schulz R, Post H, Vahlhaus C, Heusch G. 1998. Ischemic Preconditioning in Pigs: A Graded Phenomenon Its Relation to Adenosine and 
Bradykinin. Circulation. 98:1022-1029.

Sookhai S, Wang JJ, McCourt M, Kirwan W, Bouchier-Hayes D, Redmond P. 2002. A novel therapeutic strategy for attenuating neutrophilmediated lung injury in vivo. Ann Surg. 235: 285-291.

Steurer M, Schlapfer M, Zgraggen B, et al. 2009. The volatile anaesthetic sevoflurane attenuates lipopolysaccharide-induced injury in alveolar macrophages. Clin Exp Immunol. 155:224-30.

Takao Y, Mikawa K, Nishina K, et al. 2005. Attenuation of acute lung injury with propofol in endotoxemia. Anesth Analg. 100: 810-6.

Tassiopoulos A, Hakim T, Finck C, Pedoto A, Hodell M, Landas S, McGraw D. 1998. Neutrophil sequestration in the lung following acute aortic occlusion starts during ischaemia and can be attenuated by tumour necrosis factor and nitric oxide blockade. Eur J Vasc Endovasc Surg. $16: 36-42$.

Toller WG, Kersten JR, Pagel PS, Hettrick DA, Warltier DC. 1999. Sevoflurane reduces myocardial infarct size and decreases the time threshold for ischemic preconditioning in dogs. ANESTHESIOLOGY. 91:1437- 46 .

Tomai F, Crea F, Gaspardone A, Versaci F, Ghini AS, Ferri C, Desideri G, Chiariello L, Gioffre' PA. 1999. Effects of naloxone on myocardial ischemic preconditioning in humans. J Am Coll Cardiol. 33:1863-9.

Vianna PT, Castiglia YM, Braz JR, Viero RM, Beier S, Vianna Filho PT, Vitória A, Reinoldes Bizarria Guilherme G, de Assis Golim M, Deffune E. 2009. Remifentanil, isoflurane, and preconditioning attenuate renal ischemia/reperfusion injury in rats. Transplant Proc. 41:4080 -2.

Votta-Velis EG, Minshall RD, Visintine DJ, et al. 2007. Propofol attenuates endotoxin-induced endothelial cell injury, angiotensin-converting enzyme shedding, and lung edema. Anesth Analg. 105: 1363-70.
Wagner J, Strosing KM, Spassov SG, Lin Z, Engelstaedter H, Tacke S, Hoetzel A, Faller S. 2018. Sevoflurane posttreatment prevents oxidative and inflammatory injury in ventilator-induced lung injury. PLoS One. 22;13(2):e0192896.

Watanabe K, Iwahara C, Nakayama H, Iwabuchi K, Matsukawa T, Yokoyama K, Yamaguchi K, Kamiyamaand Y, Inada E. 2013. Sevoflurane suppresses tumour necrosis factor- -induced inflammatory responses in small airway epithelial cells after anoxia/reoxygenation. British Journal of Anaesthesia. 110 (4): 637-45.

Wu Q, Gui P, Wu J, et al. 2011. Effect of limb ischemic preconditioning on myocardial injury in patients undergoing mitral valve replacement surgery. A randomized controlled trial. Circ J. 75 (8):1885-1889.

Xin P, Zhu W, Li J, et al. 2010. Combined local ischemic postconditioning and remote perconditioning recapitulate cardioprotective effects of local ischemic preconditioning. Am J Physiol Heart Circ Physiol. 298 (6): H1819-H1831.

Xu B, Gao X, Xu J, et al. 2011. Ischemic postconditioning attenuates lung reperfusion injury and reduces systemic proinflammatory cytokine release via heme oxygenase 1. J Surg Res. 166 (2): e157-e164.

Yu Y, Gao M, Li H, Zhang F, Gu C. 2013. Pulmonary Artery Perfusion with Anti-Tumor Necrosis Factor Alpha Antibody Reduces Cardiopulmonary Bypass-Induced Inflammatory Lung Injury in a Rabbit Model. PLoS One. 27;8(12):e83236.

Zaugg M, Lucchinetti E, Uecker M, Pasch T, Schaub MC. 2003. Anaesthetics and cardiac preconditioning. Part I: Signalling and cytoprotective mechanisms. Br J Anaesth. 91:551-65.

Zhou W, Zeng D, Chen R, Liu J, Yang G, Liu P, Zhou X. 2010. Limb Ischemic Preconditioning Reduces Heart and Lung Injury After an Open Heart Operation in Infants. Pediatr Cardiol. 31:22-29. 